\title{
A Computational study on the performance and emissions parameters mapping of a ship propulsion system
}

\author{
Gerasimos Theotokatos ${ }^{1}$ and Vasileios Tzelepis \\ ${ }^{1}$ corresponding author \\ email: gerasimos.theotokatos@strath.ac.uk \\ Department of Naval Architecture and Marine Engineering \\ University of Strathclyde, Glasgow, UK
}

\begin{abstract}
In the present paper, the mapping of the performance and emission parameters of a merchant vessel propulsion system over the ship operating envelope was carried out by using a model capable of representing the ship propulsion system behaviour. The model was developed based on a modular approach and was implemented in the MATLAB/Simulink environment. The various parts of the propulsion engine as well as the shafting system, the propeller and ship hull were represented by separate submodels having the appropriate interface for exchanging the required variables to each other. The output of the model includes the performance and emission parameters of the engine as well as the operating parameters of the propeller and ship. Initially, the propulsion engine operation under steady state conditions was simulated and the predicted engine performance parameters results were validated. Then, simulations of the ship propulsion system operating points at various resistance curves were performed. Based on the derived results, the mapping of the ship propulsion system performance and emissions parameters was presented and their variation throughout the ship operating envelope was discussed. Finally, an example of using the derived results in order to minimise the fuel consumption and $\mathrm{CO}_{2}$ emissions for a typical ship route is presented and discussed.
\end{abstract}

Keywords: Propulsion system modelling, mean value engine model, performance and emissions parameters mapping, two-stroke marine Diesel engines 


\section{Introduction}

As the worldwide shipping activities have been continuously growing, more pressure is put forth towards the greener shipping in order to limit the shipping industry environmental impact. This was initiated by the regulatory framework imposed by the International Maritime Organisation (IMO) and the national authorities for the limitation of the non-greenhouse emissions, which include nitrogen oxides (NOx) and sulphur oxides (SOx), as well as the greenhouse gaseous emissions; mainly the carbon dioxide $\left(\mathrm{CO}_{2}\right)$. The recent amendments of the international legislation [1] and the introduction of the Energy Efficiency Design Index (EEDI) [2] as well as the Ship Energy Efficiency Management Plan (SEEMP), which can be based on the Energy Efficiency Operational Indicator (EEOI) [3], focus on the reduction of both $\mathrm{CO}_{2}$ emissions and fuel consumption throughout the ship lifetime. Thus, apart from the environmental benefits, the ship operational cost can be confined, which positively affect the competitiveness of the shipping companies.

A number of measures can be used for complying with the existing legislation [4]. The reduction of ship sailing speed, known as slow steaming [5], can reduce the consumed fuel, $\mathrm{CO}_{2}$ emissions and ship operational cost but it cannot be considered as an acceptable measure for increasing the ship propulsion plant efficiency and achieving a value for the energy efficiency design index below the imposed baseline value [1-2]. Measures that positively affect the ship energy efficiency [4] include the improved hull and ship structure designs, which result in ship resistance decrease, as well as more efficient propulsors designs that can inrease the ship propulsive efficiency. On the other hand, for obtaining an environmentally cleaner operation of the ship propulsion plant, the engine manufactures have been introduced new engine designs with higher stroke to bore ratio that can be combined with a large diameter propeller [6-7], electronically controlled engine versions [7-8] in which the engine settings can be adjusted over the engine operating envelope to optimise the engine performance, and waste heat recovery systems [9-11]. In addition, retrofitting packages for engine cylinders cut off, turbocharger isolation and turbochargers with variable geometry turbines have been presented [12-13], so that the engine operation, especially at slow steaming, becomes more efficient,. However, for complying with the more stringent regulations for NOx and SOx emissions [13-14], techniques such as exhaust gas recirculation (EGR), selective catalytic reaction (SCR) and exhaust gas scrubbers must be used [16-17], which however deteriorate the engine efficiency and increase the $\mathrm{CO}_{2}$ gaseous emissions. Alternatively, "cleaner" fuels such as liquefied natural gas (LNG) can be used for the ship propulsion 
and auxiliary engines, thus significantly reducing $\mathrm{CO}_{2}$ emissions and almost eliminating NOx and $\mathrm{SOx}$ emissions [18].

Apart from the improved designs of the ship propulsion system, the efficient operation of the ship is also crucial for constraining the fuel consumption and gaseous emissions over the ship lifetime. In that respect, engine monitoring systems [19-20], which include recently developed sensors (e.g. sensors for continuously measuring the engine cylinder pressure [21]), have been evolved and used onboard ships for adjusting the engine settings in order to achieve the highest engine efficiency. In addition, fleet management systems as well as optimum routing software packages [22] are used for reducing the fleet consumed fuel, and thus the fleet operating cost. In these systems, the propulsion system initial performance parameters must be provided, so that the propulsion system operation is evaluated by comparing the performance parameters recorded values with their initial values, so that corrective actions are taken in order to obtain the desirable operation.

In that respect, the engine shop and ship trials measurements can be used to provide the ship propulsion baseline data. However, since the ship propulsion system will operate in a variety of conditions throughout the ship lifetime depending on the ship resistance variation and the engine degrading, the enrichment of the initial set of data is desirable. The quantification of the ship propulsion system behaviour over the ship operating envelope can be addressed by mapping the ship propulsion system performance and emissions parameters. These maps can be then used for optimising the propulsion system throughout its lifetime, for adjusting the engine settings where significant deviations are observed, for taking decisions for the engine and ship maintenance schedule, as well as for obtaining better understanding of the ship propulsion system operation and the interaction between the system components. The propulsion system mapping can be accomplished by using appropriate ship propulsion system modelling techniques.

Various types of models have been used in the past for the simulation of marine engines and the ship propulsion system under steady state and transient conditions. The more commonly used types are the zero dimensional models [23-28] and the cycle mean value engine models [29-33]. The former are more complex, require a large number of input data and their execution time lasts longer but can very accurately represent the engine processes. The latter are simpler and therefore less laborious, require limited amount of input data and their execution time is quite reasonable, whereas they can predict the engine performance parameters with adequate accuracy. The cycle mean value models consider the 
engine cylinders flow process taking place continuously, thus neglecting the intermittent nature of the engine cylinders processes, and as a result, they can provide the engine cycle averaged temporal evolution of the engine operating parameters, whereas their in-cycle variation (e.g. per degree of crank angle) cannot be calculated. More detailed description of the mean value engine models is given in [33]. For enhancing the models user friendliness, the concept of modular model development has been previously used for the modelling marine diesel engine and the ship propulsion system components [33-35]. According to that approach, the model is built using separate blocks for each one of the system components, whereas the required variables exchanging between the blocks is accomplished using appropriate connections. The advantage of this approach is that each submodel can be easily replaced by a more detailed or a simpler one without interacting with the other model elements. The mapping of engine performance and emissions parameters is a technique that has been used in previous research studies. In [36], the marine engine and its turbocharger parameters maps were used for the development of the engine control system. In [37] and [38], maps of engine cylinders parameters created based on a zero dimensional model and then used for the control schemes development and testing of the propulsion system of an ice-class ship operating at ice breaking conditions.

In the present paper, the propulsion system performance and emission parameters of a handymax size vessel were mapped using the results derived by a modular approach built model, which was implemented in the MATLAB/Simulink environment. The mean value engine model presented in a previous study of the first author [33] was modified to incorporate appropriate blocks for the propeller and ship longitudinal movement modelling. Separate blocks were used for representing the parts of the ship propulsion system including the engine components, the shafting system, the propeller and the ship hull, whereas the appropriate interface and connections were used for exchanging the required variables between the model blocks. The engine cylinders were modelled using a mean value modelling approach, the engine scavenging air and exhaust receivers were considered open thermodynamic systems, whereas the turbocharger compressor and turbine were represented by their steady state performance maps. The engine exhaust gas carbon dioxide $\left(\mathrm{CO}_{2}\right)$ and sulphur dioxide $\left(\mathrm{SO}_{2}\right)$ emissions were calculated using the approach of perfect combustion in excess air, whereas the nitrogen oxides (NOx) emissions were estimated based on typical values of NOx composition of the exhaust gas. The propeller is modelled using polynomial equations for the non-dimensional torque and thrust coefficients, whereas the ship surge dynamics is taken into consideration for calculating the ship 
longitudinal velocity and position. First, the ship propulsion engine was simulated under steady state conditions in order to validate the derived engine performance parameters results. Then, simulation runs for a number of ship propulsion system operating points in various values of ship resistance were performed and the derived results were used for mapping the propulsion system performance and emissions parameters. The variation of the propulsion system performance and emission parameters throughout the ship operating envelope is discussed. Finally, an example of minimising the consumed fuel and emitted $\mathrm{CO}_{2}$ gaseous emissions during the ship operation in a typical route based on the mapping of the propulsion system performance and emission parameters is presented and discussed.

\section{Ship propulsion plant modelling}

The propulsion plant installation of a typical merchant vessel consists of the main engine, the shafting system and the propeller. Depending on the vessel type and size, the ship main engine can be two-stroke or four-stroke turbocharged marine Diesel engine. The shafting system comprises the connecting shafts and the bearings and additionally for the four-stroke type engines, a gear box installed between the engine crankshaft and the propeller shaft. In high power installations, a shaft generator is often installed in order to produce the required electric power during ship voyages, where the engine operates at relatively high load. In the case of merchant vessels propulsion plant installation, the propeller is usually of fixed pitch type, although during the last years, designs with controllable pitch propellers have also been used.

In this work, the ship propulsion system modelling was implemented in MATLAB/Simulink environment following a modular approach, as it is depicted in Figure 1. Each part of the engine is modelled using a separate block, which exchanges variables with the adjacent blocks of the model through the appropriate connections. The marine Diesel engine is modelled using flow receivers (control volumes) interconnected between flow elements. Fixed fluid elements having with constant pressure and temperature are used for modelling the engine boundaries. Shaft elements are used for calculating the engine crankshaft and turbocharger shaft rotational speeds. The engine governor element, which is used to adjust the engine fuel rack position, is considered to be of the proportionalintegral (PI) type and incorporates the appropriate fuel rack limiters. The propeller and ship elements are used for calculating the propeller and ship parameters, respectively. 


\section{Engine parts modelling}

The engine scavenging air and exhaust gas receivers are modelled as flow receivers, whereas the engine cylinders, compressor and turbine are modelled as flow elements. The engine ambient conditions are represented by fixed fluid elements of constant pressure and temperature. The properties of the working medium either air or gas are considered to be functions of temperature and air-fuel equivalence ratio. The flow elements use as input the pressure, temperature and the properties of the working medium contained in the adjacent elements (flow receiver(s) or fixed fluid), whereas their output includes the mass flow and energy rates entering and exiting the flow element as well as the absorbed (for the case of compressor) or produced torques. The mass and energy flows are provided as input in the adjacent flow receiver elements, whereas the torques are required as input in the shaft elements. The output of turbocharger shaft element, i.e. the turbocharger speed, is forwarded to the compressor and turbine elements. The output of the crankshaft element includes the engine and propeller rotational speeds; the former is supplied as input to the engine cylinders and engine governor elements, whereas the latter is advanced in the propeller element.

The flow receiver elements are modelled using the open thermodynamic system concept [39-40]. The working medium mass and temperature are calculated using the following differential equations, which are derived by applying the mass and energy conservation laws in each volume, respectively:

$$
\begin{gathered}
\frac{d m}{d t}=\dot{m}_{\text {in }}-\dot{m}_{\text {out }} \\
\frac{d T}{d t}=\frac{\dot{Q}_{h t}+(\dot{m} h)_{\text {in }}-(\dot{m} h)_{\text {out }}-u \frac{d m}{d t}}{m c_{v}}
\end{gathered}
$$

where $\dot{m}_{i n},(\dot{m} h)_{i n}$ are the mass flow and energy rates entering the flow receiver and $\dot{m}_{\text {out }},(\dot{m} h)_{\text {out }}$ are the mass flow and energy rates exiting the flow receiver, respectively. Subsequently, the working medium pressure is calculated using the ideal gas law.

No heat transfer is taken into account for the scavenging air receiver, whereas the transferred heat from the gas contained in the exhaust gas receiver to the ambient is calculated using the exhaust gas receiver overall heat transfer coefficient and heat transfer area, as follows [41]:

$$
\dot{Q}_{h t}=k_{h t} A_{h t}\left(T_{E R}-T_{a m b}\right)
$$

The overall heat transfer coefficient in the exhaust receiver is calculated using the following 
equation, which has been derived by manipulating a Nusselt-Reynolds number correlation for gas flowing in pipes [41]:

$$
k_{h t}=k \overline{\dot{m}}^{0.75}
$$

where $k$ is a constant and $\overline{\dot{m}}$ is the average of exhaust receiver entering and exiting mass flow rates.

For the case of two-stroke Diesel engines, the engine cylinders bank is regarded as a flow element, where the incoming air mass flow rate is calculated considering the equivalent of two consecutive orifices, each one representing the cylinders scavenging ports and exhaust valve, respectively [42]. Thus, the engine cylinders air mass flow rate is calculated based on subsonic flow consideration [40] using the equivalent cylinders flow area, the air properties as well as the pressures upstream and downstream of the engine cylinders, as follows:

$$
\begin{gathered}
\dot{m}_{a}=c_{d} A_{e q} p_{S C} / \sqrt{R_{a} T_{S C}} f\left(p r_{c y l}, \gamma_{\alpha}\right), \quad p r_{c y l}=p_{E R} / p_{S C}, \\
f\left(p r_{c y l}, \gamma_{\alpha}\right)=\sqrt{\left[2 \gamma_{\alpha} /\left(\gamma_{\alpha}-1\right)\right]\left(p r_{c y l}{ }^{2 / \gamma_{\alpha}}-p r_{c y l}{ }^{\left(\gamma_{\alpha}+1\right) / \gamma_{\alpha}}\right)}
\end{gathered}
$$

The equivalent orifice geometric area can be estimated using the instantaneous area variations for an engine cycle of the intake ports and exhaust valves, as follows [42]:

$$
A_{e q}=\frac{z_{c y l}}{\Delta \phi_{c y}} \int_{0}^{\Delta \phi_{c y}} \frac{A_{s p}(\phi) A_{e v}(\phi)}{\sqrt{A_{s p}^{2}(\phi)+A_{e v}^{2}(\phi)}} \mathrm{d} \phi
$$

The mass flow rate of the exhaust gas exiting the engine cylinders is found by adding the mass flow rates of the air entering the engine cylinders and the injected fuel. The latter is calculated using the number of the engine cylinders, the engine rotational speed and the injected fuel mass per cylinder and per cycle, according to the following equation:

$$
\dot{m}_{f}=z_{c y l} m_{f, c y} N_{E} /(60 \mathrm{rev})
$$

The injected fuel mass per cylinder and per cycle is regarded as function of engine fuel rack position. The energy flow rate exiting the engine cylinders element is calculated by taking into consideration the energy conservation equation and the fact that a portion of the fuel energy remains in the exhaust gas; thus:

$$
(\dot{m} h)_{c y l \_d}=\dot{m}_{a} h_{a_{-} c y l \_u}+\zeta \eta_{c o m b} \dot{m}_{f} H_{L}
$$

where $\zeta$ is fuel chemical energy proportion in the exhaust gas exiting engine cylinders.

The proportion of the fuel chemical energy contained in the exhaust gas is considered to be a linear function of the engine brake mean effective pressure [42]: 


$$
\zeta=k_{z 0}+k_{z 1} \bar{p}_{b}
$$

The engine brake mean effective pressure is calculated by subtracting the friction mean effective pressure from the indicated mean effective pressure, whereas the indicated mean effective pressure is calculated using the rack position, the maximum indicated mean effective pressure of the engine and the combustion efficiency, which, in turn, is regarded as function of engine air to fuel ratio [39]. The friction mean effective pressure is considered function of the indicated mean effective pressure and the engine crankshaft speed [36]. The engine torque is calculated using the following equation:

$$
Q_{E}=\frac{\bar{p}_{b} V_{D}}{2 \pi r e v}
$$

The compressor is modelled using its steady state performance map, which is provided as input in a digitized form containing lines of the turbocharger speed, pressure ratio, corrected flow rate and efficiency. Given the turbocharger shaft speed and the compressor pressure ratio, the corrected flow rate and efficiency are calculated using interpolation. The turbocharger shaft speed is taken from the turbocharger shaft element, whereas the compressor pressure ratio is calculated by the following equation using the pressure of the fixed fluid connected upstream the compressor, the pressure of the scavenging air receiver connected downstream the compressor, the air filter pressure drop, the air cooler pressure drop, and the pressure increase in the auxiliary blower:

$$
p r_{C}=\frac{p_{S C}-\Delta p_{A C}+\Delta p_{B L}}{p_{a m b}-\Delta p_{A F}}
$$

The air filter and air cooler pressure drops are considered to be functions of the compressor air mass flow rate, whereas the blower pressure increase is regarded as function of its volumetric flow rate.

The temperature of the air exiting compressor is calculated using the temperature of the air entering the compressor and the compressor pressure ratio and efficiency, as follows:

$$
T_{C_{-} d}=T_{a t m}\left(1+\left(p r_{C}^{\left(\gamma_{a}-1\right) / \gamma_{\alpha}}-1\right) / \eta_{C}\right)
$$

The temperature of the air exiting the air cooler is calculated using the air cooler effectiveness and the temperature of the cooling water entering the air cooler; thus:

$$
T_{A C_{-} d}=T_{C_{-} d}\left(1-\varepsilon_{A C}\right)+\varepsilon_{A C} T_{w, A C}
$$

The air cooler effectiveness is assumed to be a polynomial function of the air mass flow rate. The compressor absorbed torque is calculated by the following equation: 


$$
Q_{C}=\dot{m}_{C}\left(h_{C_{-} d}-h_{C_{-} u}\right) / \omega_{T C}
$$

where the enthalpies of the air exiting the compressor and the air entering the compressor are calculated using the respective temperatures.

The turbine is modelled using its swallowing capacity and efficiency maps, which must be provided in digitized form. Given the turbine pressure ratio, the turbine mass flow rate and efficiency are calculated using interpolation.

The turbine pressure ratio is calculated using the pressure of the exhaust gas receiver, the ambient pressure downstream the engine exhaust pipe and the exhaust pipe pressure loss, as follows:

$$
p r_{T}=\frac{p_{E R}}{p_{a m b}+\Delta p_{e p}}
$$

The pressure loss of the exhaust piping system is regarded as proportional to the exhaust gas mass flow rate squared. The temperature of the gas exiting turbine is calculated using the temperature of gas entering turbine, and the turbine pressure ratio and efficiency, as follows:

$$
T_{T_{-} d}=T_{E R}\left(1-\eta_{T}\left[1-\left(1 / p r_{T}\right)^{\frac{\gamma_{e}-1}{\gamma_{e}}}\right]\right)
$$

The turbine power is derived by using the following equation:

$$
Q_{T}=\dot{m}_{T}\left(h_{E R}-h_{T, d}\right) / \omega_{T C}
$$

where the enthalpies of the gas exiting the turbine is calculated using the respective temperature, whereas the enthalpy of the gas entering the turbine is taken from the upstream exhaust gas receiver element.

The engine crankshaft and turbocharger shaft rotational speed calculation is carried out in the shafting system and turbocharger shaft elements, respectively. The former uses the engine and propeller torques fed from the engine cylinders and propeller elements, whereas the later uses the compressor and turbine torques supplied form the respective elements. The engine crankshaft and turbocharger shaft rotational speeds are calculated by integrating the following equations derived using the angular momentum conservation in the propulsion plant shafting system and the turbocharger shaft, respectively:

$$
\frac{d N_{E}}{d t}=\frac{30\left(\eta_{S h} Q_{E}-Q_{P}\right)}{\pi\left(I_{E}+I_{S h}+I_{P}+I_{e w}\right)}
$$




$$
\frac{d N_{T C}}{d t}=\frac{30\left(Q_{T}-Q_{C}\right)}{\pi I_{T C}}
$$

The engine fuel pumps rack position is adjusted by the engine governor, which is modelled using a proportional-integral (PI) controller law according to the following equation:

$$
x_{r}=x_{r, o}+k_{p} \Delta N+k_{i} \int_{0}^{t} \Delta N d t
$$

where $\Delta \mathrm{N}=\mathrm{N}_{\text {ord }}-\mathrm{N}_{\mathrm{E}}$ is the difference between the ordered engine speed and the actual engine speed. In addition, torque and scavenging pressure limiters were also incorporated in the engine governor model as proposed and used by engine manufacturers for protecting the engine integrity during fast transients [24].

\section{Exhaust Gas Emissions Calculation}

In order to calculate the engine carbon dioxide $\left(\mathrm{CO}_{2}\right)$ and sulphur dioxide $\left(\mathrm{SO}_{2}\right)$ gaseous emissions, the concept of perfect combustion in excess air was used [40], which is justified by the fact that the substances produced by the chemical reactions other than the perfect fuel combustion e.g. carbon monoxide, unburnt hydrocarbons, nitrogen oxides, etc. form less than $0.5 \%$ of the exhaust gas volume [43]. In addition, the nitrogen oxides (NOx) were estimated based on their expected concentration in the exhaust gas depending on the engine type and the used fuel $[28,43]$.

By considering the perfect combustion in excess air of $1 \mathrm{kmol}$ fuel consisting of carbon, hydrogen and sulphur denoted by the chemical formula $C_{c / M_{C}} H_{h / M_{H}} S_{s / M_{S}}$, which has a mass of $1 \mathrm{~kg}$, the following equations can be derived for calculating the produced $\mathrm{CO}_{2}$ and $\mathrm{SO}_{2}$ mole fractions as well as the number of exhaust gas moles:

$$
\begin{aligned}
& x_{\mathrm{CO}_{2}}=\frac{c / M_{C}}{n_{e}} \\
& x_{\mathrm{SO}_{2}}=\frac{s / M_{S}}{n_{e}} \\
& n_{e}=\frac{\lambda n_{s t_{o_{2}}}}{0.21}+\frac{0.25 h}{M_{H}}
\end{aligned}
$$

The number of oxygen moles required in the case of stoichiometric combustion of $1 \mathrm{~kg}$ fuel is calculated using the reactants and products molar balance according to the following equation: 


$$
n_{s t_{O_{2}}}=\frac{c}{M_{C}}+\frac{0.25 h}{M_{H}}+\frac{s}{M_{S}}
$$

The mean molar mass (or molecular weight) of exhaust gas is calculated as follows:

$$
M_{e}=\frac{\lambda n_{s t_{O_{2}}} M_{\text {air }} / 0.21+1}{\lambda n_{s t_{O_{2}}} / 0.21+0.25 h / M_{H}}
$$

The mass flow rate of each exhaust gas compound is calculated using the molar fraction and molar mass of the considered compound, as well as the exhaust gas average molar mass and mass flow rate, using the following equation:

$$
\dot{m}_{i}=x_{i} \frac{M_{i}}{M_{e}} \dot{m}_{e}
$$

The nitrogen oxides (NOx) mass flow rate can be calculated either by applying equation (26) using the estimated exhaust gas NOx volume fraction or by taking into account the specific NOx emissions. The ideal gas consideration, which is the most usual for the working media of internal combustion engines, was followed; thus species mole fractions are considered to be equal to the respective volume fractions.

\section{Propeller Modelling}

The propeller element uses as input the propeller rotational speed and the ship speed, which are supplied from the engine shaft element and the ship element, respectively. Its output variables include the propeller torque and thrust; the former is forwarded in the engine shaft element, whereas the latter is provided in the ship element. The ship propeller torque and thrust are calculated by using the following equations based on the non-dimensional coefficients of torque and thrust respectively, the sea water density the propeller rotational speed and the propeller diameter:

$$
\begin{aligned}
& Q_{P}=k_{Q} \rho_{s w} N_{P}^{2} D_{P}^{5} \\
& T_{P}=k_{T} \rho_{s w} N_{P}^{2} D_{P}^{4}
\end{aligned}
$$

The non-dimensional torque and thrust coefficients in open water conditions are calculated using the interpolation polynomials for Wageningen B-screw series [44] in the first quadrant. Appropriate corrections for Reynolds number [44] and Japanese Modified-AU propeller series [45] were taken into account. The propeller pitch to diameter ratio, expanded area ratio, number or blades and advance coefficient are required as input. In the case of the fixed propeller type, the pitch to diameter ratio at 
$70 \%$ of the propeller radius is used.

The propeller advance coefficient depends on the speed of advance, which is the linear velocity of the water arriving in the propeller, the propeller rotational speed and the propeller diameter, according to the following equation:

$$
J=\frac{V_{A}}{N_{P} D_{P} / 60}
$$

The speed of advance is calculated by applying the following equation using the ship linear velocity and the ship wake fraction coefficient; the latter can be estimated either from model tests or using semi-empirical formulas and is usually assumed as constant taking values in the region from 0.20 to 0.45 for ships with a single propeller operating in a wide range of ship velocities [46]:

$$
V_{A}=(1-w) V_{S}
$$

The propeller open water efficiency is defined by the following equation [44]:

$$
\eta_{P}=\frac{k_{T} J}{2 \pi k_{Q}}
$$

When a propeller is submerged in water and rotates as part of the vessel shafting system, the propeller polar moment of inertia is increased due to the water entrained by the propeller movement. The entrained inertia depends on the geometrical characteristics of the propeller and can be calculated only experimentally. There are several semi-empirical equations that estimate the entrained inertia [47]. The inertia of the entrained water by the propeller is calculated according to the following equation using the entrained water coefficient:

$$
I_{e w}=\eta_{e w} I_{P}
$$

The entrained water coefficient is regarded as function of the propeller blades angle of attack, which is derived as the difference between the blades geometric pitch angle and blades hydrodynamic pitch angle, as follows:

$$
\alpha=\arctan \left(\frac{p / D_{P}}{\pi}\right)-\arctan \left(\frac{V_{A}}{V_{u}}\right)
$$

The mean circumferential blade velocity at the position of $70 \%$ of the propeller diameter is calculated by the following equation:

$$
V_{u}=0.7 \pi D_{P} N_{P} / 60
$$

The propeller real slip ratio, which is a parameter used in order to indicate the propeller loading 
under various operating conditions, is calculated by:

$$
S R_{R}=1-\frac{V_{A}}{p N_{P} / 60}
$$

The overall propulsive efficiency, which depends on the propeller open water efficiency, propeller relative rotative efficiency, hull efficiency and shafting system efficiency, is calculated using the following equation [44]:

$$
P C=\frac{P_{e f f}}{P_{b}}=\eta_{P} \eta_{R} \eta_{H} \eta_{S h}
$$

The shafting system efficiency was regarded as function of engine load [48]; the propeller relative rotative efficiency was taken as constant, whereas the hull efficiency, which is defined as the ratio of the effective power for a hull with appendages to the thrust power developed by the propeller, is calculated using the thrust deduction coefficient and the ship wake fraction factor, as follows:

$$
\eta_{H}=\frac{1-t}{1-w}
$$

\section{Ship Longitudinal Movement Modelling}

The ship longitudinal velocity is calculated by integrating the following equation, which is derived by applying the ship motion dynamics:

$$
\left(m_{S}+m_{\text {hydro }}\right) \frac{d V_{S}}{d t}=T_{P}-F-R_{S}
$$

The ship resistance is taken as polynomial function of ship longitudinal velocity and it was estimated at calm water conditions by using the Holtrop method [49]. The increase of the ship resistance depends on the hull fouling and in the encountered environmental conditions including wave height and direction, wind magnitude and direction and sea current. In very adverse weather conditions and especially when the ship sailing in head seas and high sea states, the ship resistance can increase as much as $100 \%$ in comparison to the respective value at calm water conditions [50].

The mass of the ship is calculated by multiplying the ship volume of displacement with the sea water density. The ship surge-surge added mass is used for taking into account the hydrodynamic force exerted in the ship due to its surge longitudinal acceleration into a fluid and was calculated according to the semi-empirical equation given in [51] as function of the ship displacement and hull block coefficient. 
The thrust deduction is calculated using the thrust deduction factor, as follows:

$$
F=t T_{P}
$$

where the thrust deduction factor can be considered to have a constant value, typically in the region from 0.12 to 0.30 for ships with a single propeller [50], or to be dependent on the ship longitudinal velocity.

In order to estimate the total ship propulsion system efficiency the following variable was used, which was defined as the ship effective power divided by the engine fuel power, i.e.:

$$
\eta_{P S}=\frac{P_{E f f}}{\dot{Q}_{f}}=\eta_{b} P C
$$

\section{Results and Discussion}

The propulsion system of a Handymax size product carrier type vessel was simulated using the model described above. The vessel has deadweight of $37600 \mathrm{MT}$, and uses as propulsion engine the MAN B\&W 6S46MC-C7, which is a marine Diesel engine of the two-stroke type. The engine crankshaft is directly connected to the ship fixed pitch propeller via the ship shafting system. The engine is turbocharged operating on the constant pressure turbocharging system concept using one turbocharger unit. An air cooler unit is installed in order to cool the hot air exiting the compressor. For that type of engine, the engine geometric data are published in the engine project guide [52], whereas the engine performance parameters can be calculated using the engine manufacturer web-based software Computerized Engine Application System-Engine Room Dimensioning (CEAS ERD) [53]. The main ship, propulsion engine and propeller parameters are summarised in Table 1.

For setting up the examined ship propulsion system model, a number of input data were used. These included the engine, propeller and ship geometric data, the turbocharger compressor and turbine performance maps, the engine ambient conditions, the constants of engine model equations and the ship resistance curve. Initial conditions are also required for the variables that are calculated by integrating differential equations, i.e. the engine/propeller shaft and turbocharger shaft rotational speeds, the pressure and temperature of air and gas contained in the engine receivers and the ship longitudinal velocity.

In order to validate the engine model, the engine steady state operation was simulated at various operating points in the region from $25 \%$ to $100 \%$ of the engine maximum continuous rating (MCR) 
point. The engine load was considered to vary according to the propeller law equation corresponding to the curve passing through the engine MCR point. In that case, the model ship element block was not used and the propeller element was replaced by a simpler model according to which the engine propeller torque was proportional to the propeller speed squared. The error in percentage or absolute value between the recorded values of the engine performance parameters during the engine shop trials and the respective predicted values are presented in Table 2. Predictions of sufficient accuracy were obtained for the engine load region from $75 \%$ to $100 \%$ of engine MCR point, where the observed percentage errors were lower than $2 \%$. For engine operation at lower loads, errors up to $10 \%$ were recorded. This is attributed to the fact that the model constants were adjusted for the region of $90 \%$ engine load and therefore, greater deviations of the predicted engine performance parameters are expected for the low engine load region. However, the engine model predictions are regarded as satisfactory and the model can be used with fidelity for the study presented below.

Having validated the mean value engine model, the propulsion plant of the handymax size merchant vessel, which main characteristics are given in Table 1, was simulated. The blocks of the propeller and the ship elements that are described in the previous section were used in the model. The ship resistance for calm water and full load draft sailing conditions were estimated based on the ship geometric characteristics according to the Holtrop method [49], whereas the ship surge-surge added mass at full loaded conditions was found to be $6.9 \%$ of the ship displacement. The propulsion system behaviour was examined for various percentages of the ship resistance increase, from $10 \%$ to $55 \%$ in comparison to her resistance at full load draft in calm water conditions. The ship resistance curves as well as the propulsion system operating points that were simulated are presented in Figure 2. In total, 48 operating points were simulated. Each simulation run was performed as follows. First, the appropriate resistance curve polynomial coefficients were provided as input to the ship element block. Then, the engine ordered speed was selected and the appropriate estimations of the model required initial conditions were given. The simulation run was performed providing an adequate execution time, so that the model parameters (especially the ship longitudinal velocity) reach their steady state values.

The results derived from the simulation runs are presented in Figures 3-11. The predicted engine brake power and rotational speed versus ship speed at the examined operating points are shown in Figure 3. The predicted curves of engine brake power versus engine rotational speed superimposed on the engine load diagram are presented in Figure 4. The engine power vs. rotational speed curve for the 
case of $55 \%$ increase in ship resistance passes through the engine MCR point. For each ship resistance curve, the predicted engine brake power vs. rotational speed curve has an almost cubic form. By using curve fitting techniques to correlate the engine power and rotational speed for each set of predicted engine operating points, power formulae were obtained with their exponent values ranging between 3.048 and 3.013, which are very close to 3 that is taken into account to describe the engine powerrotational speed variation according to the propeller law. As it can be deduced from the results presented in Figures 2 and 3, to maintain the same ship speed in the case of ship resistance increase, higher percentage increase of the engine power is required. For the case of $30 \%$ ship resistance increase, the required power increase is found to be around $40 \%$, whereas for the case of $55 \%$ ship resistance increase, an engine power increase of approximately $75 \%$ is required to maintain the same ship speed. In addition, in cases of increased ship resistance, higher engine/propeller shaft rotational speed is required in order to retain the same ship speed and as a result, the propeller operates at higher slip ratio values, which reduces its efficiency.

The engine fuel mass flow rate and the air-fuel equivalence ratio vs. ship speed are presented in Figure 5. The fuel mass flow rate, and as a consequence, the engine fuel consumption increases for higher ship resistance, since the engine has to produce more power. On the other hand, the engine airfuel equivalence ratio reduces for higher ship resistance since the engine air mass flow rate, which is supplied by the turbocharger compressor, does not increase at the same rate. This can cause greater thermal loading on the engine. At low engine loads, the electric driven blower is activated and as a result, slightly higher air mass flow rates can be obtained in the engine. This has as a consequence slightly increased values of the engine air-fuel equivalence ratio as it is shown in Figure 5.

The curves of engine brake specific fuel consumption (corrected at ISO conditions) vs. ship speed are presented in Figure 6. It can be inferred by comparing Figures 5 and 6 that as the ship resistance increases, and thus more fuel must be burned due to the higher demand in engine power in order to retain the ship speed, lower engine brake specific fuel consumption is obtained. This is explained as the minimum point of brake specific fuel consumption is usually achieved in engine load range from $75 \%$ to $90 \%$ of engine MCR point, depending on the engine optimisation settings. For the examined ship propulsion system, the most efficient engine operation (lower brake specific fuel consumption equal to approximately $179 \mathrm{~g} / \mathrm{kWh}$ ) is obtained at 13.3 knots for the case of ship resistance increase $55 \%$ and 13.85 knots for the case of $40 \%$ ship resistance increase. 
The curves of the turbocharger shaft rotational speed vs. ship speed and the compressor pressure ratio vs. air mass flow rate are presented in Figure 7. As the ship resistance increases, the turbocharger operates at higher rotational speeds in order to feed the engine cylinders with the required higher air mass flow. However, since the examined engine is of the two-stroke type, the compressor pressure ratio vs. air mass flow operating points lies on a single curve, which denotes that the variation of compressor pressure ratio vs. mass flow is not dependent on the engine rotational speed. That curve superimposed on the compressor performance map must lie on areas of high compressor efficiency and be sufficiently far from the compressor surge line.

The curves of the engine exhaust receiver gas temperature and the temperature of the exhaust gas exiting the engine vs. ship speed are given in Figure 8. As the ship resistance increases, higher engine power is required, which is obtained by burning more fuel into the engine cylinders, whereas the respective rise in the air delivered by the turbocharger compressor is smaller. Therefore, lower values of the air-fuel equivalence ratio are observed, which results in increased values of the temperature of the gas contained in the engine exhaust receiver. At very low engine loads, the electric driven blower is activated and as a result the engine air mass flow rate is slightly increased. Thus, the greater amount of low temperature air entering into the engine cylinders has as a consequence the slight reduction of the exhaust receiver gas temperature for the low values of ship speed. The temperature of the exhaust gas exiting the turbine depends on the efficiency of the turbine according to the equation 16 . Therefore, the temperature of the exhaust gas exiting the turbine takes its lower value, which is approximately $230^{\circ} \mathrm{C}$ in the case of usage of Marine Gas Oil (MGO) fuel, for the engine operating points in which the maximum turbocharger turbine efficiency is obtained.

The curves for overall propulsive efficiency and total propulsion system efficiency vs. ship speed are shown in Figure 9. The former depends on the hull efficiency, the propeller open water and relative rotative efficiencies and the shafting system efficiency. The term that has the greater influence is the propeller open water efficiency, so the maximum point of each curve coincides with the maximum of the respective propeller efficiency curve. The overall propulsive efficiency reduces as the ship resistance increases. Values in the range from 0.67 to 0.77 were predicted for the examined ship overall propulsive efficiency for the investigated operating points. The maximum value of each curve of the propulsive efficiency is observed for lower ship speeds, which is justified by the fact that the propulsion system of the examined ship was optimised for engine operation at slow steaming. 
The overall ship propulsion system efficiency is the product of engine brake efficiency and the overall propulsive efficiency. The predicted values lie in the region from 0.30 to 0.35 ; the maximum values were observed at the points of maximum engine efficiency (lower engine brake specific fuel consumption). The total propulsion system efficiency also reduces as the ship resistance increases. An alternative interpretation of the data presenting in Figure 9 can be that a percentage from $30 \%$ to $35 \%$ of the energy provided with the fuel to the ship propulsion engine is only finally used to move the ship.

The predictions for the carbon dioxide $\left(\mathrm{CO}_{2}\right)$, nitrogen oxides $(\mathrm{NOx})$ and sulphur dioxide $\left(\mathrm{SO}_{2}\right)$ gaseous emissions of the propulsion engine in the cases of using Heavy fuel Oil (HFO) containing $3 \mathrm{wt} \%$ sulphur and Marine Gas Oil (MGO) fuel containing $0.1 \mathrm{wt} \%$ sulphur are presented in Figures 10 and 11 . The two fuels have different lower heating values; namely $39500 \mathrm{~kJ} / \mathrm{kg}$ for the case of HFO and $41500 \mathrm{~kJ} / \mathrm{kg}$ for the case of MGO. The NOx emissions were estimated based on appropriate assumption for exhaust gas NOx volume concentration, which was taken as $1600 \mathrm{ppm}$ for the case of Heavy Fuel Oil (HFO) and 1500 ppm for the case of Marine Gas Oil (MGO) at exhaust gas oxygen volume concentration $13 \%$. These values correspond to specific NOx emissions approximately 12.4 $\mathrm{g} / \mathrm{kWh}$ for the HFO and $11.6 \mathrm{~g} / \mathrm{kWh}$ for the MGO and comply with the IMO Tier II limits.

Quite significant amount of $\mathrm{CO}_{2}$ is released to the atmosphere for each day of vessel operation; for the case of the ship sailing at 12 knots, 48.8 tons $\mathrm{CO}_{2}$ per day are produced when the ship resistance is $10 \%$ increased, whereas the produced amount of $\mathrm{CO}_{2}$ becomes approximately 74.3 tons per day when the ship resistance is 55\% increased from its calm water/clean hull value. As the ship resistance increases, higher engine brake power is required to retain the ship speed, greater amount of fuel must be burnt into the engine cylinders, and as a result, greater amount of $\mathrm{CO}_{2}$ is produced. The two stoke marine Diesel engines operate using HFO, which is much cheaper compared with the MGO. However, about $3 \%$ greater amount of $\mathrm{CO}_{2}$ is produced in the case of $\mathrm{HFO}$ usage in comparison to the operation of the engine using MGO fuel in the same operating point. This is attributed to the fact that the HFO lower heating value is approximately 5\% less than the respective one of MGO, and therefore, $5 \%$ greater amount of HFO is required and $2 \%$ more exhaust gas is produced in order for the engine to operate with the same power. The fuel carbon and hydrogen contents, which also affect the $\mathrm{CO}_{2}$ production, have also slightly different values (carbon content: $86 \mathrm{wt} \%$ for $\mathrm{HFO}$ and $87.7 \mathrm{wt} \%$ for MGO, hydrogen content: $10.5 \mathrm{wt} \%$ for HFO and $12.2 \mathrm{wt} \%$ for MGO). The produced amount of NOx is considerable; for the case of the ship sailing at 12 knots and HFO is used, about 0.95 tons NOx per day 
are produced when the ship resistance is $10 \%$ increased, whereas the produced amount of NOx becomes approximately 1.5 tons per day when the ship resistance is $55 \%$ increased from its calm water/clean hull value. Lower NOx emissions by $6 \%$ are estimated in the case of MGO usage due to the slightly lower exhaust gas NOx composition and mass flow. However, these reductions of $\mathrm{CO}_{2}$ and NOx are not in the extent that the existing or the forthcoming legislation requires, and therefore, the use of a low sulphur fuel is not considered as an acceptable solution from the $\mathrm{CO}_{2}$ and $\mathrm{NOx}$ emissions reduction perspective.

On the other hand, the $\mathrm{SO}_{2}$ gaseous emissions can be significantly reduced in the case of using MGO fuel, as it can be seen in Figure 11, where reduction of $\mathrm{SO}_{2}$ emissions by $97 \%$ is obtained. In that case, the ship operation cost is expected to rise even in the case of using as fuel a low sulphur HFO. The price of a low sulphur MGO fuel is presently $70-80 \%$ higher than the HFO price and rise in the low sulphur fuels price is foreseen for the future due to the their expected increased demand as larger areas will be characterised as Sulphur Emissions Control Areas (SECAs) [54].

Based on the above presented results, an example of the ship operation at full load draft in a typical route [55] of $4000 \mathrm{NM}$ is given below. The terminal parts as well as the transient periods of the examined ship voyage were excluded from the below analysis. Assuming that the required time of sailing is 14 days, an average ship velocity of 11.9 knots must be retained throughout the ship route. Three different cases for the prevailing sea state conditions throughout the ship voyage, which affect the ship resistance, were examined. According to the first one, the ship sails for 4 days at adverse weather conditions and high sea states and for the rest 10 days of her voyage at moderate sea states. In the second case, half of the voyage time is spent at adverse sea conditions and the rest at moderate sea states. The third one is the worst case, where adverse and moderate conditions were considered to be encountered for 10 and 4 days, respectively. In all the examined cases, the ship resistance increase was taken $55 \%$ for the cases of sailing at adverse conditions, whereas $10 \%$ resistance increase was assumed for the part of voyage where moderate sea states are faced.

The results concerning the $\mathrm{HFO}$ consumption as well as the produced amount of $\mathrm{CO}_{2}$ are presented in Table 3. For each case, the following options are taken into account: sailing at constant speed or sailing with different ship speed at the parts of the route where the ship faces different weather conditions. The values of ship speed that results in minimisation of the fuel consumption and $\mathrm{CO}_{2}$ production throughout the ship voyage for each one of the examined cases are given in Table 3 . As it 
can be inferred from the results presented in Table 3, the greater duration of the voyage part at adverse whether condition is, the greater are the consumed fuel amount and the $\mathrm{CO}_{2}$ emitted to the environment. In the first examined case with the shorter duration of the ship voyage at adverse conditions, the minimum fuel consumption is obtained by reducing the ship velocity by 1.4 knots (from 11.9 to 10.5 knots) for the part of the voyage at adverse conditions and increasing the ship velocity to 12.46 knots for the rest of the voyage where moderate conditions prevail. By using a sailing scenario of varying ship velocity instead of retaining the ship velocity constant, $5.7 \mathrm{t}$ of HFO can be saved (the consumed HFO amount reduced from $243 \mathrm{t}$ to $237.5 \mathrm{t}$ ), whereas the respective decrease in $\mathrm{CO}_{2}$ was calculated to be approximately $18 \mathrm{t}$ (from $766 \mathrm{t}$ to $748 \mathrm{t}$ ). Similar figures were also recorded in the other two cases, where $\mathrm{HFO}$ savings of $2.8 \%$ and $2.2 \%$, respectively, and similar reductions of $\mathrm{CO}_{2}$ can be obtained by lowering the ship speed when the ship sails at adverse conditions. However, as the duration of the ship sailing at increased resistance conditions becomes longer, the margin in for reducing the ship speed becomes less and the possible saving of fuel diminishes.

\section{Conclusions}

The performance and emission parameters mapping of the propulsion system of a Handymax size vessel was performed based on a modular built model implemented in the MATLAB/Simulink computational environment. The propulsion system operation was simulated at various ship resistance conditions in the range from the resistance at full load draft and calm water conditions up to $55 \%$ increase. The main conclusions derived from this work are summarised as follows.

The developed mean value engine model can sufficiently represent the engine operation and therefore, it can be used to provide engine performance and emissions parameter predictions, which are required in order to interpret the engine behaviour. The combined engine-propeller-ship modelling can be used for mapping the engine and emissions parameters and supporting the analysis of the propulsion system behaviour over the entire ship operating envelope.

Increased ship resistance results in higher demand in engine power and rotational speed in order to retain the ship speed and as a result, in increased fuel consumption and gaseous emissions production. However, the engine operation is more efficient, since usually the engine is oversized in order to be capable of covering the extreme ship power demands and the engine maximum efficiency is obtained in the region of 75 to $90 \%$ of engine MCR operating point. 
The overall ship propulsive efficiency and the total propulsion system efficiency deteriorate as the ship resistance increases owing to the fact that, apart from the engine, the rest parts of the propulsion system, from which the ship propeller has the most determinant effect, become less efficient. The predicted total propulsion system efficiency values of the examined ship were in the region from $30 \%$ to $35 \%$, which means that every part of the ship propulsion system has to be investigated in order to obtain an increase of the present figures.

The engine gaseous emissions also increase for higher values of the ship resistance. In the case of HFO usage, the amount of produced $\mathrm{CO}_{2}$ and NOx emissions were calculated $3 \%$ and $6 \%$ respectively greater than the ones predicted for the MGO fuel usage, but such a fuel change (from HFO to MGO) cannot be considered as acceptable from the $\mathrm{CO}_{2}$ and $\mathrm{NOx}$ emissions reduction perspective. Using low sulphur fuels containing $0.1 \mathrm{wt} \%$ sulphur, the production of $\mathrm{SO}_{2}$ gaseous emissions can be reduced up to $97 \%$ compared to a $3 \mathrm{wt} \%$ sulphur heavy fuel oil.

The developed ship propulsion model can be used to minimise the fuel and emissions of the ship throughout her voyages. In the case of the ship sailing encountering varying environmental conditions, which affect the ship resistance, the adjustment of the ship speed can lead in reduction of the fuel consumption and emissions. For the examined ship, considering a voyage of 14 days, which contains a part at adverse sea conditions and a part at moderate sea states, and assuming different ship resistance increase in each part, a reduction of the fuel consumption by $2.2 \%$ to $3 \%$ was calculated when the ship sails at slightly reduced speed for the part of voyage facing adverse conditions and at slightly increased speed in the rest part of her voyage.

The usefulness of the mapping of the propulsion system performance and emissions for minimising the fuel consumption and gaseous emissions during ship operation was evidenced. Either precalculated data for the propulsion system performance and emissions mapping or a pre-set up model could also be used in an automated system for the online adjustment of the ship propulsion system operational parameters in order to minimise of consumed fuel and produced emissions throughout the ship lifetime. In addition, they can be used in combination with a ship monitoring system for the identification of engine operation and its deviation from its expected performance.

Apart from using the developed model for investigating the steady state performance and transient response of the ship propulsion system, it can also be used for designing and testing control schemes for the ship main engine and the propulsion system components. However, such a model should be 
treated carefully for the simulation of electronically controlled versions of marine engines especially when they are combined with adjustable turbocharging systems and control devices. In these cases, a combined approach of a mean value-zero dimensional models could be used in order to exploit the advantages of the mean value engine models, i.e. the modularity and low execution time, and the engine cylinders parameters prediction accuracy that the zero-dimensional models provide.

\section{Funding}

This research received no specific grant from any funding agency in the public, commercial, or not-for-profit sectors. 


\section{References}

1. IMO. Resolution MEPC.203(62) Amendments to the annex of the protocol of 1997 to amend the international convention for the prevention of pollution from ships, 1973, as modified by the protocol of 1978 relating thereto (Inclusion of regulations on energy efficiency for ships in MARPOL Annex VI). International Maritime Organization. London. 15 July 2011. MEPC 62/24/Add.1. 2011.

2. IMO. Resolution MEPC.212(63) Guidelines on the method of calculation of the attained energy efficiency design index (EEDI) for new ships. International Maritime Organization. London. 2 March 2012. MEPC 63/23. 2012.

3. IMO. Resolution MEPC.213(63) Guidelines for the development of a ship energy efficiency management plan (SEEMP). International Maritime Organization. London. 2 March 2012. MEPC 63/23. 2012.

4. IMO. Air pollution and energy efficiency-Estimated $\mathrm{CO}_{2}$ emissions reduction from introduction of mandatory technical and operational energy efficiency measures for ships. International Maritime Organisation. London. 31 October 2011. MEPC 63/INF.2. 2011.

5. Wiesmann A. Slow steaming-a viable long-term option? Wärtsilä Technical Journal: Marine/InDetail. 02/2010. pp. 49-55.

6. MAN Diesel \& Turbo. G-Type Engine-Revolutionary Ultra-Long-Stroke. Publication no: 55100104-01ppr. July 2012 MAN Diesel \& Turbo Copenhagen Denmark.

7. Wärtsilä. Marine Solutions, 2nd ed. Wärtsilä Corporation, Publication no: SP-EN-DBAC136254. $08 / 2012$.

8. MAN Diesel \& Turbo, Marine Engine IMO Tier II Programme 2013. Publication no: 4510-001200ppr. Jan 2013. MAN Diesel \& Turbo SE. Germany.

9. MAN Diesel \& Turbo. Waste Heat Recovery System (WHRS) for Reduction of Fuel Consumption, Emissions and EEDI. Publication no: 5510-0136-01ppr. December 2012. MAN Diesel \& Turbo. Copenhagen. Denmark.

10. Rupp M. Green ships on the high seas. ABB Review. 4/2007. pp. 58-61.

11. Schmid H. Less emissions through waste heat recovery. Green Ship Technology Conference. London. 28-29 April 2004. London. UK.

12. Brown D. Helping shipowners cut fuel bills with Wärtsilä low-speed engines. Wärtsilä Technical Journal: Marine/InDetail. 01/2009. pp. 34-37.

13. MAN Diesel \& Turbo. 2012. SFOC Optimisation Methods for MAN B\&W Two-stroke IMO Tier II Engines. Publication no: 5510-0099-00ppr. August 2012. MAN Diesel \& Turbo. Copenhagen. Denmark.

14. http://www.imo.org/OurWork/Environment/PollutionPrevention/AirPollution/Pages/Nitrogenoxides-(NOx)---Regulation-13.aspx

15. http://www.imo.org/OurWork/Environment/PollutionPrevention/AirPollution/Pages/Sulphuroxides-(SOx)---Regulation-14.aspx

16. Brown D, Holtbecker R. Next steps in exhaust emissions control for Wärtsilä low-speed engines. Wärtsilä Technical Journal: Marine/InDetail. 01/2007. pp. 34-37.

17. MAN Diesel \& Turbo. Tier III Two-Stroke Technology. Publication no: 5510-0136-01ppr. August 2012. MAN Diesel \& Turbo. Copenhagen. Denmark.

18. Bui Y. 2011. Machinery Concepts and LNG for meeting IMO Tier III rules. Wärtsilä Technical Journal: Marine/InDetail. 01/2011. pp. 31-38.

19. Ignatius J., Räsänen J.-E., Tervo K. Huttunen O. EMMA Ship Energy Manager Know, understand and change. ABB marine. 2012.

20. MAN Diesel \& Turbo. Engine Management Concept for LNG Carriers. 5510-0024-03ppr. August 2012. MAN Diesel \& Turbo. Copenhagen. Denmark. 
21. Rolle S., Wiesmann A. Combustion Control and Monitoring of two-stroke engines. Wärtsilä Technical Journal: Marine/InDetail. 02/2011. pp. 52-57.

22. Shao W., Zhou P., Thong S.K. Development of a novel forward dynamic programming method for weather routing. J Mar Sci Technol. 2012. Vol. 17. 239-251.

23. Kyrtatos N.P., Koumbarelis I. Performance prediction of next-generation slow speed diesel engines during ship manoeuvers. Trans IMarE. Vol.106, Part I. 1994. 1-26.

24. Kyrtatos N.P., Theodossopoulos P., Theotokatos G., Xiros N. Simulation of the overall ship propulsion plant for performance prediction and control. In Proceedings of the Conference on Advanced marine machinery systems with low pollution and high efficiency (MarPower '99). Newcastle upon Tyne. UK. 25-26 March 1999. pp. 103-114.

25. Hountalas D.T. Prediction of marine diesel engine performance under fault conditions. Applied Thermal Engineering. 20. 2000. 1753-1783.

26. Campora U., Figari M. Numerical Simulation of Ship Propulsion transients and Full Scale Validation. Proceedings of Institution of Mechanical Engineers, Part M, Journal of Engineering for the Maritime Environment, Vol. 217. 2003. pp. 41-52.

27. Livanos G.A., Theotokatos G., Kyrtatos N.P. Simulation of large marine two-stroke diesel engine operation during fire in the scavenging air receiver. Journal of Marine Engineering and Technology. A3. 2003. 9-16.

28. Scappin F., Stefansson S.H., Haglind F., Andreasen A., Larsen U. Validation of a zero-dimensional model for prediction of NOx and engine performance for electronically controlled marine twostroke diesel engines. Applied Thermal Engineering. 37. 2012. 344-352.

29. Woodward J.B., Latorre R.G. Modeling of diesel engine transient behavior in marine propulsion analysis. SNAME Trans. 1984. 92. 33-49.

30. Hendrics E. Mean value modeling of large turbocharged two-stroke diesel engines. SAE technical paper no 890564.1989.

31. Chesse P., Chalet D., Tauzia X., Hetet J. F., Inozu B. Real-time performance simulation of marine diesel engines for the training of navy crews. Mar. Technol. 2004, 41(3), 95-101.

32. Grimmelius H., Mesbahi E., Schulten P., Stapersma D. The use of diesel engine simulation models in ship propulsion plant design and operation. In Proceedings of the 25th CIMAC World Congress on Combustion engine technology. Vienna. Austria. 21-24 May 2007. paper 227.

33. Theotokatos G. On the cycle mean value modelling of a large two-stroke marine diesel engine. Proc. IMechE Part M: J. Engineering for the Maritime Environment. 2010. Vol. 224. 193-205.

34. Lambropoulos V., Kyrtatos N.P. Modular Simulation of Marine Propulsion Systems Using an Engineering Building Block Approach, ISME 6th International Symposium on Marine Engineering. Tokyo. Japan. October 23-27 2000. Vol. II. pp. 641-648.

35. Dimopoulos GG., Kakalis N.M.P. An integrated modeling framework for the design operation and control of marine energy systems. In: Proceedings of CIMAC congress 2010. Bergen. Norway 1417 June 2010. paper no: 154.

36. Xiros N. Robust Control of Diesel Ship Propulsion. Springer-Verlag. London. 2002.

37. Livanos G.A., Simotas G.N., Kyrtatos N.P. Tanker Propulsion Plant Transient Behavior during Ice Braking Conditions. 16th International Offshore and Polar Engineering Conference (ISOPE 2006). San Franscisco. USA. 2006.

38. Livanos G., Papalamprou G., Kyrtatos N. P., Christou A. Electronic engine control for ice operation of tankers. In Proceedings of the 25th CIMAC World Congress on Combustion engine technology. Vienna. Austria. 21-24 May 2007. paper 44.

39. Watson N., Janota M.S. Turbocharging the internal combustion engine. 1982. Macmillan. Basingstoke. Hampshire.

40. Heywood J.B. Internal combustion engines fundamentals. 1988. McGraw-Hill. New York.

41. Rohsenow W.M., Hartnett J.P., Ganic E. Handbook of Heat Transfer Fundamentals, 2nd ed. 1985. McGraw-Hill. New York. 
42. Meier E. A simple method of calculation and matching turbochargers. Publication CH-T 120 163E. 1981. Brown Boveri \& Company Ltd. Baden. Switzerland.

43. Henningsen S. Air Pollution from Large Two-Stroke Diesel Engines and Technologies to Control It. In: Handbook of Air pollution from Internal Combustion Engines: Pollutant Formation and Control. Sher E(ed). 1998. Academic Press Ltd. London.

44. Carlton J.S. Marine Propellers and Propulsion, 2nd Ed. 2007. Butterworth-Heinemann. Oxford. UK.

45. HydroComp. Correlating propeller performance with $\mathrm{Kt} / \mathrm{Kq}$ multipliers. Technical Report no: 101. 2003. HydroComp Inc. USA.

46. Bertram V. Practical ship hydrodynamics. 2nd ed. 2012. Elsevier Ltd. UK.

47. Korotkin A.I. Added masses of ship structures. 2nd ed. 2009. Springer Science and Business Media B.V.

48. SNAME. Marine diesel power plant practices. T\&R Bulletin no: 3-49. June 1990. The Society of Naval Architects and Marine Engineers. Jersey City. USA.

49. Holtrop J., Mennen G. An approximate power prediction method. Int Shipbuilding Prog. 329, 1982.166-170.

50. MAN Diesel \& Turbo. Basic principles of ship propulsion. Publication no: 5510-0004-02ppr. August 2012. MAN Diesel \& Turbo. Copenhagen. Denmark.

51. Oltmann P. Identification of hydrodynamic damping derivatives-A pragmatic approach. Proceedings of the International Conference on Marine Simulation and Ship Manoeuvrability (MARSIM'03). Vol. III. 575-583. 25-28 August 2003.Kanazawa. Japan.

52. MAN Diesel \& Turbo. MAN B\&W S46MC-C7 Project Guide, 4th ed. January 2009. MAN Diesel \& Turbo. Copenhagen. Denmark.

53. http://www.mandieselturbo.com/ceas/index.html

54. EMSA. The $0.1 \%$ sulphur in fuel requirement as from 1 January 2015 in SECAs-An assessment of available impact studies and alternative means of compliance. Technical Report. 13 December 2010. European Maritime Safety Agency.

55. Laulajainen R. Oil product tanker geography with emphasis on the Handysize segment. 2011. Fennia. 189(1). 1-19. 


\section{APPENDIX}

\section{Notation}

\begin{tabular}{|c|c|}
\hline$A$ & $\operatorname{area}\left(\mathrm{m}^{2}\right)$ \\
\hline$b s f c$ & brake specific fuel consumption (g/kWh) \\
\hline$c, h, s$ & weight composition of fuel in carbon, hydrogen and sulphur $(\mathrm{kg} / \mathrm{kg}$ fuel) \\
\hline$c_{d}$ & discharge coefficient (-) \\
\hline$c_{v}$ & specific heat at constant volume $(\mathrm{J} / \mathrm{kgK})$ \\
\hline$D$ & diameter $(\mathrm{m})$ \\
\hline$F$ & thrust deduction $(\mathrm{N})$ \\
\hline$I$ & polar moment of inertia $\left(\mathrm{kgm}^{2}\right)$ \\
\hline$J$ & propeller advance coefficient (-) \\
\hline$h$ & specific enthalpy $(\mathrm{J} / \mathrm{kg})$ \\
\hline$H_{L}$ & fuel lower heating value $(\mathrm{J} / \mathrm{kg})$ \\
\hline$k$ & coefficients, constants \\
\hline$k_{Q}, k_{T}$ & propeller non-dimensional torque and thrust coefficients (-) \\
\hline$k_{p}, k_{i}$ & engine governor proportional and integral constants \\
\hline$m$ & $\operatorname{mass}(\mathrm{kg})$ \\
\hline$m_{f, c y}$ & mass of injected fuel per cylinder per cycle $(\mathrm{kg})$ \\
\hline$\dot{m}$ & mass flow rate $(\mathrm{kg} / \mathrm{s})$ \\
\hline$M$ & molar mass (molecular weight) $(\mathrm{kg} / \mathrm{kmol})$ \\
\hline$n$ & number of moles (kmol) \\
\hline$N$ & rotational speed (rpm) \\
\hline$p$ & pressure $\left(\mathrm{N} / \mathrm{m}^{2}\right)$, pitch $(\mathrm{m})$ \\
\hline$p r$ & pressure ratio (-) \\
\hline $\bar{p}$ & mean effective pressure (bar) \\
\hline$P$ & power (W) \\
\hline$P C$ & overall propulsive efficiency (-) \\
\hline$Q$ & torque $(\mathrm{Nm})$ \\
\hline$\dot{Q}$ & heat transfer rate $(\mathrm{W})$ \\
\hline rev & revolutions per cycle (-) \\
\hline$R$ & gas constant $(\mathrm{J} / \mathrm{kgK})$, resistance $(\mathrm{N})$ \\
\hline$S R_{R}$ & propeller real slip ratio (-) \\
\hline$t$ & time (s), thrust deduction factor (-) \\
\hline$T$ & temperature $(\mathrm{K})$, thrust $(\mathrm{N})$ \\
\hline$u$ & specific internal energy $(\mathrm{J} / \mathrm{kg})$ \\
\hline$V_{A}$ & Speed of advance(m/s) \\
\hline$V_{D}$ & displacement volume $\left(\mathrm{m}^{3}\right)$ \\
\hline$V_{S}$ & ship velocity $(\mathrm{m} / \mathrm{s})$ \\
\hline
\end{tabular}






\section{Subscripts}

a

$\mathrm{amb}$

air

ambient

AC air cooler

AF air filter

b brake

BL blower

comb combustion

cy cycle

cyl cylinder

C compressor, carbon

$\mathrm{CO}_{2} \quad$ carbon dioxide

d downstream

e exhaust gas

ef efficiency

eff effective

ep exhaust pipe

eq equivalent

ev exhaust valve

ew entrained water

E engine

ER exhaust receiver

f fuel

ht heat transfer 


\begin{tabular}{|c|c|}
\hline hydro & hydrodynamic \\
\hline $\mathrm{H}$ & hull, hydrogen \\
\hline in & inlet \\
\hline $\max$ & maximum \\
\hline MCR & maximum continuous rating \\
\hline o & initial conditions \\
\hline out & outlet \\
\hline $\mathrm{O}_{2}$ & oxygen \\
\hline $\mathrm{pr}$ & pressure ratio \\
\hline$P$ & propeller \\
\hline PS & propulsion system \\
\hline $\mathrm{R}$ & rotative \\
\hline $\mathrm{sp}$ & scavenging ports \\
\hline st & stoichiometric \\
\hline sw & sea water \\
\hline S & ship, sulphur \\
\hline $\mathrm{Sh}$ & shafting system \\
\hline $\mathrm{SC}$ & scavenging receiver \\
\hline $\mathrm{SO}_{2}$ & sulphur dioxide \\
\hline $\mathrm{T}$ & turbine \\
\hline $\mathrm{TC}$ & turbocharger \\
\hline $\mathrm{u}$ & upstream \\
\hline $\mathrm{w}$ & cooling medium \\
\hline \multicolumn{2}{|c|}{ Abbreviations } \\
\hline $\mathrm{CO}_{2}$ & carbon dioxide \\
\hline EEDI & energy efficiency design index \\
\hline EEOI & energy efficiency operational indicator \\
\hline EGR & exhaust gas recirculation \\
\hline HFO & heavy fuel oil \\
\hline IMO & International Maritime Organisation \\
\hline ISO & International Organization for Standardization \\
\hline LNG & liquefied natural gas \\
\hline MCR & maximum continuous rating \\
\hline MGO & marine gas oil \\
\hline MVEM & mean value engine modelling \\
\hline NOx & nitrogen oxides \\
\hline SCR & selective catalytic reaction \\
\hline SEEMP & ship energy efficiency management plan \\
\hline $\mathrm{SOx}$ & sulphur oxides \\
\hline $\mathrm{SO}_{2}$ & sulphur dioxide \\
\hline
\end{tabular}




\section{List of figure captions}

Figure 1: Ship propulsion plant model implementation in MATLAB/Simulink environment

Figure 2: Ship resistance curves with superimposed the points in which the ship propulsion system operation was simulated

Figure 3: Engine brake power (top) and rotational speed (bottom) vs. ship speed

Figure 4: Engine load diagram and operation lines for the examined ships resistance curves (M: MCR point, Line 3: Speed Limit, Line 4: Torque/Speed Limit, Line 5: MCR torque line, Line 7: MCR Power Line, Line 8: Overload Limit, Line 9: Sea Trial Speed Limit)

Figure 5: Engine fuel mass flow rate (top) and air-fuel equivalence ratio (bottom) vs. ship speed

Figure 6: Brake specific fuel consumption vs. ship speed

Figure 7: Turbocharger shaft speed vs. ship speed (top) and compressor pressure ratio vs. air mass flow rate (bottom)

Figure 8: Exhaust receiver gas temperature (top) and temperature of the exhaust gas exiting the engine (bottom) vs. ship speed

Figure 9: Overall ship propulsive efficiency (top) and total propulsion plant efficiency (bottom) vs. ship speed

Figure 10: $\mathrm{CO}_{2}$ emissions (top) and NOx emissions (bottom) for HFO and low sulphur MGO vs. ship speed

Figure 11: $\mathrm{SO}_{2}$ emissions for HFO (top) and low sulphur MGO (bottom) vs. ship speed 
TABLE 1: Ship Propulsion System parameters

\begin{tabular}{lll}
\hline \multicolumn{3}{c}{ Ship Parameters } \\
\hline Type & Chemical/Oil Product Carrier \\
Size & 37600 & $\mathrm{MT}$ \\
Length overall & 185 & $\mathrm{~m}$ \\
Breadth & 27.5 & $\mathrm{~m}$ \\
Depth & 17 & $\mathrm{~m}$ \\
Draft (design) & 9.9 & $\mathrm{~m}$ \\
Displacement & 39.200 & $\mathrm{MT}$ \\
\hline \multicolumn{3}{c}{ Propulsion Engine Parameters } \\
\hline Engine type & $6 \mathrm{~S} 46 \mathrm{MC}-\mathrm{C} 7$ & \\
Number of cylinders & 6 & \\
Bore & 460 & $\mathrm{~mm}$ \\
Stroke & 1932 & $\mathrm{~mm}$ \\
Brake Power (at MCR point) & 7860 & $\mathrm{~kW}$ \\
Engine speed (at MCR point) & 129 & $\mathrm{rpm}$ \\
BMEP (at MCR point) & 19 & $\mathrm{bar}$ \\
Turbocharger units & $1 \mathrm{x}$ ABB TPL73 \\
\hline \multicolumn{4}{l}{} \\
\hline Type & Propeller Parameters \\
Systematic series & Fixed Pitch \\
Diameter & Japanese MAU & \\
Number of blades & 5.6 & $\mathrm{~m}$ \\
Pitch at 70\% of radius & 4 & - \\
Expanded Area & 4.2 & $\mathrm{~m}$ \\
\hline
\end{tabular}

Table 2: Steady state simulation results, comparison with shop tests data

\begin{tabular}{lcccccc}
\hline Engine Load (\% MCR) & & $\mathbf{1 0 0}$ & $\mathbf{9 0}$ & $\mathbf{7 5}$ & $\mathbf{5 0}$ & $\mathbf{2 5}$ \\
\hline & $\%$ & 0.00 & -0.12 & -0.01 & 0.04 & 0.13 \\
Brake power & $\%$ & -0.01 & 0.03 & -0.04 & -0.08 & 0.12 \\
Specific fuel oil consumption (ISO conditions) & $\%$ & 0.01 & -0.08 & 0.02 & 0.04 & 0.14 \\
Brake mean effective pressure & $\%$ & -0.74 & -0.44 & 0.13 & 3.86 & 9.37 \\
Turbocharger speed & arr & 0.037 & 0.043 & 0.029 & -0.090 & -0.017 \\
Scavenging air receiver pressure & bar & -0.001 & 0.036 & 0.027 & -0.094 & -0.026 \\
Exhaust gas receiver pressure & arr & 0.038 & 0.007 & 0.002 & 0.004 & 0.009 \\
Cylinders pressure drop & $\%$ & 0.85 & -0.42 & 0.41 & -0.08 & -0.09 \\
Scavenging air receiver temperature & $\%$ & 6.21 & 6.23 & 6.15 & 6.89 & 0.59 \\
Exhaust gas receiver temperature & $\%$ & -0.94 & 0.19 & 1.56 & 3.99 & -4.31 \\
Exhaust gas temperature after turbocharger & $\%$ & -0.64 & -0.74 & -1.39 & 4.24 & 3.64 \\
Air mass flow rate & $\%$ & -0.01 & -0.09 & -0.06 & -0.05 & 0.26 \\
Fuel mass flow rate & $\%$ & -0.63 & -0.65 & -1.24 & 4.29 & 3.38 \\
Air-fuel ratio & $\%$ & 0.03 & -0.01 & 0.04 & -0.02 & -0.08 \\
Mechanical efficiency & $\%$ & 1.58 & 1.44 & 1.97 & 6.10 & 9.77 \\
Compressor pressure ratio & $\%$ & -0.44 & -0.87 & -0.96 & 5.07 & 2.09 \\
Turbine pressure ratio & & & & & & \\
\hline
\end{tabular}


Table 3: Example of fuel consumption and $\mathrm{CO}_{2}$ reduction for a specific ship route






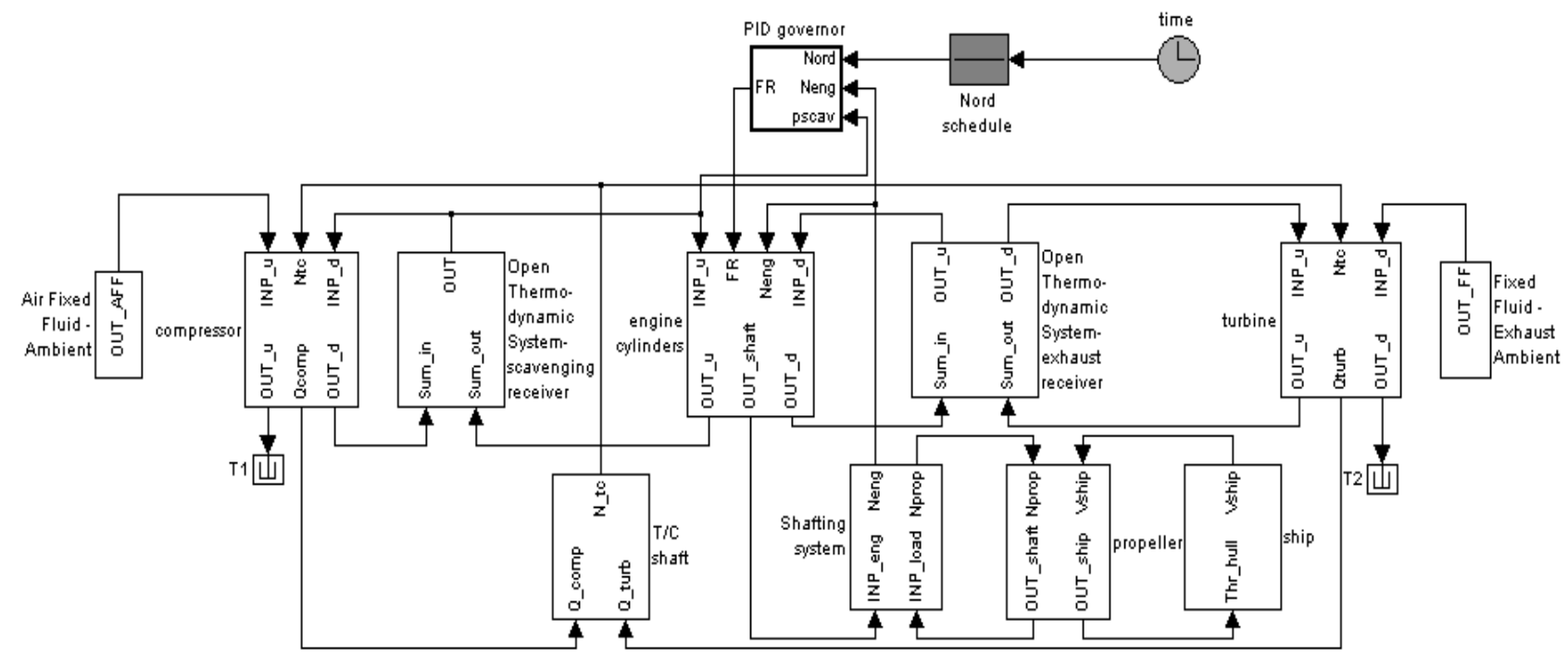

Figure 1: Ship propulsion plant model implementation in MATLAB/Simulink environment

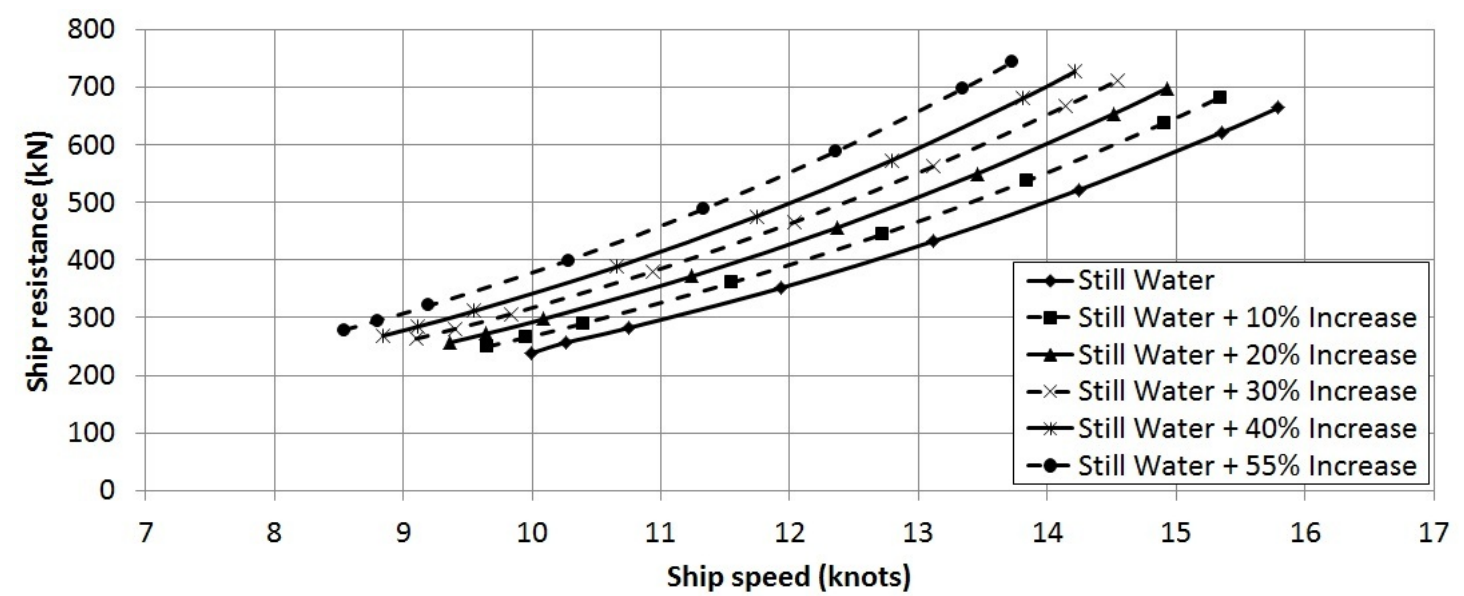

Figure 2: Ship resistance curves with superimposed the points in which the ship propulsion system operation was simulated 

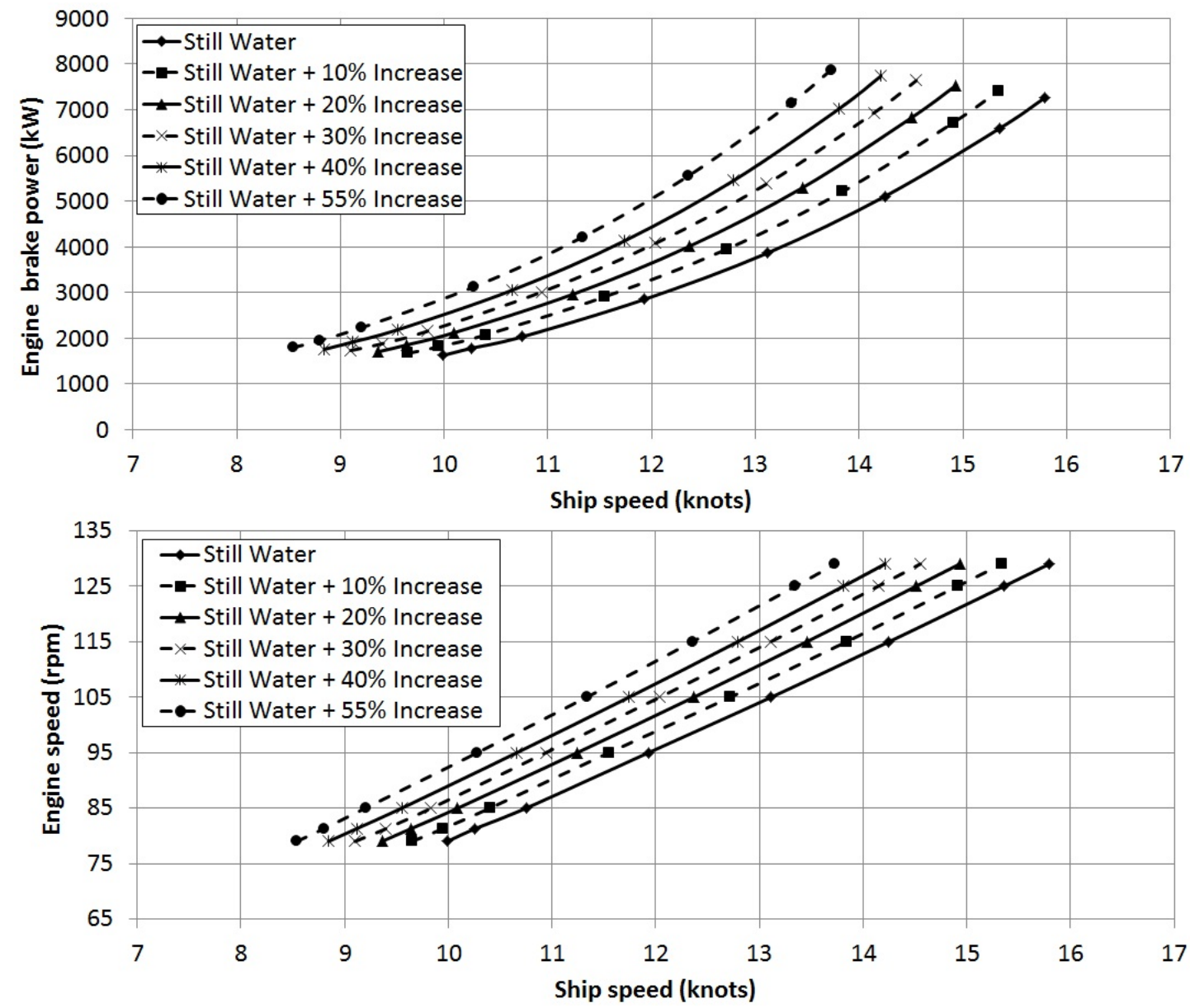

Figure 3: Engine brake power (top) and rotational speed (bottom) vs. ship speed

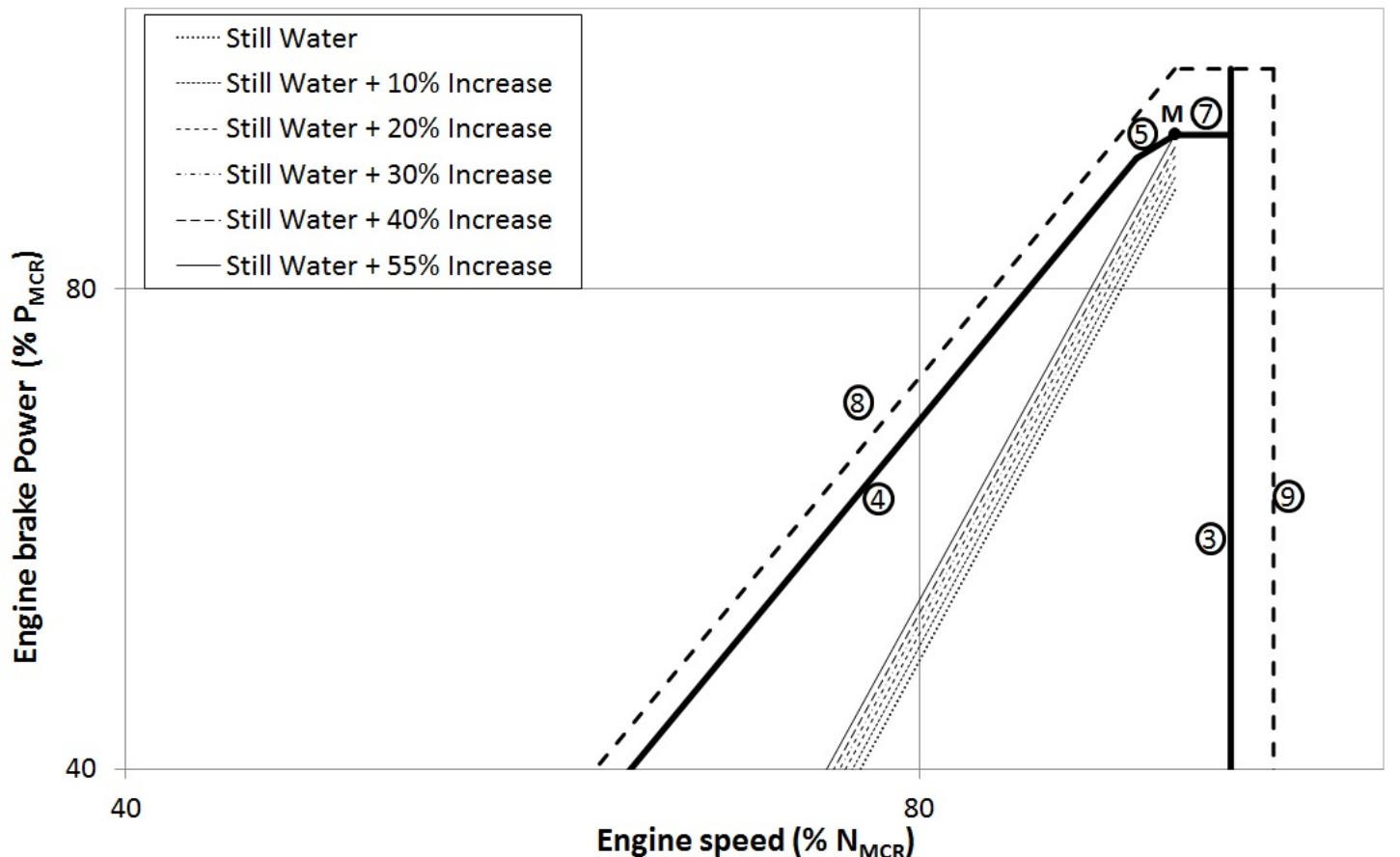

Figure 4: Engine load diagram and operation lines for the examined ships resistance curves (M: MCR point, Line 3: Speed Limit, Line 4: Torque/Speed Limit, Line 5: MCR torque line, Line 7: MCR Power Line, Line 8: Overload Limit, Line 9: Sea Trial Speed Limit) 



Figure 5: Engine fuel mass flow rate (top) and air to fuel equivalence ratio (bottom) vs. ship speed

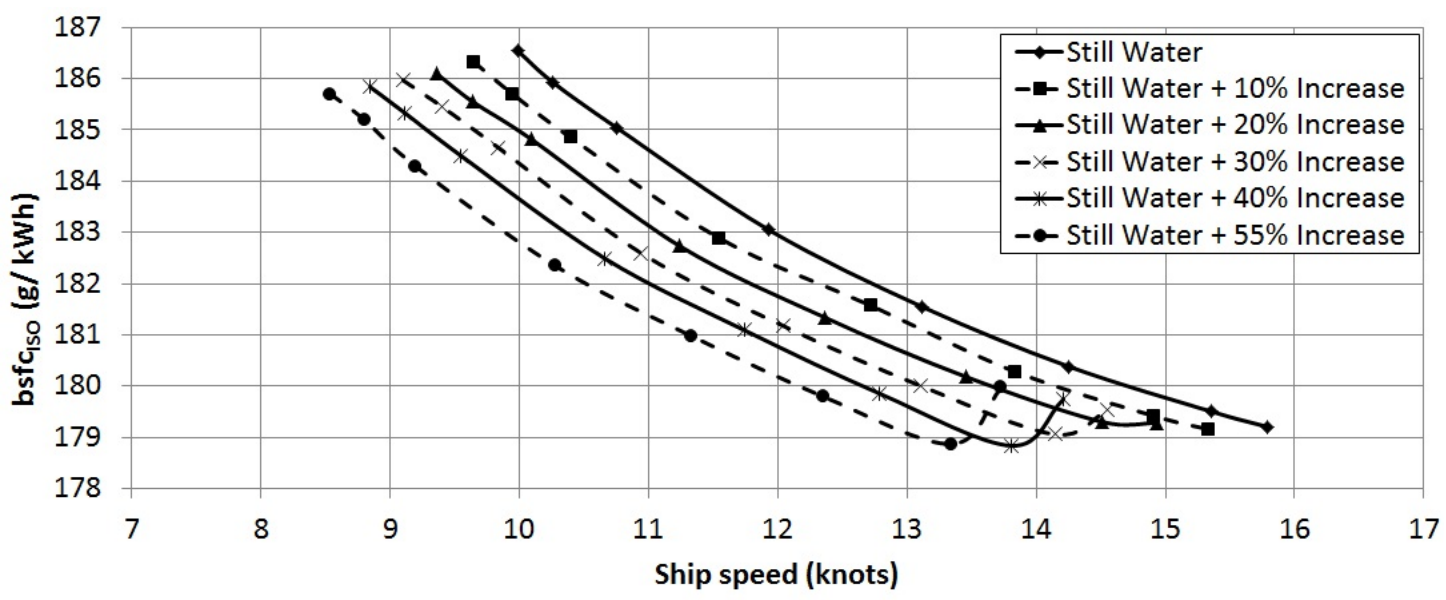

Figure 6: Brake specific fuel consumption vs. ship speed 

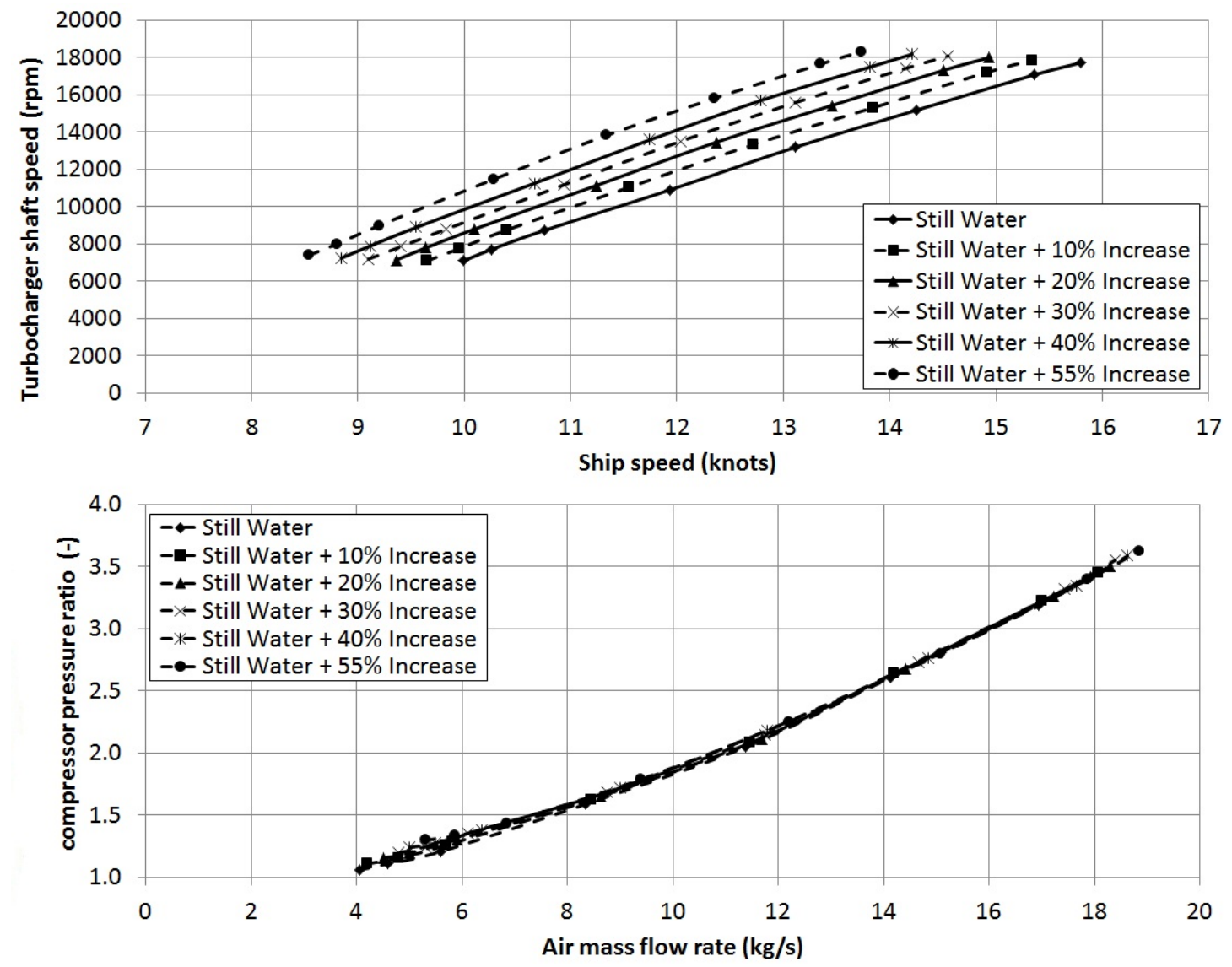

Figure 7: Turbocharger shaft speed vs. ship speed (top) and compressor pressure ratio vs., air mass flow rate (bottom) 

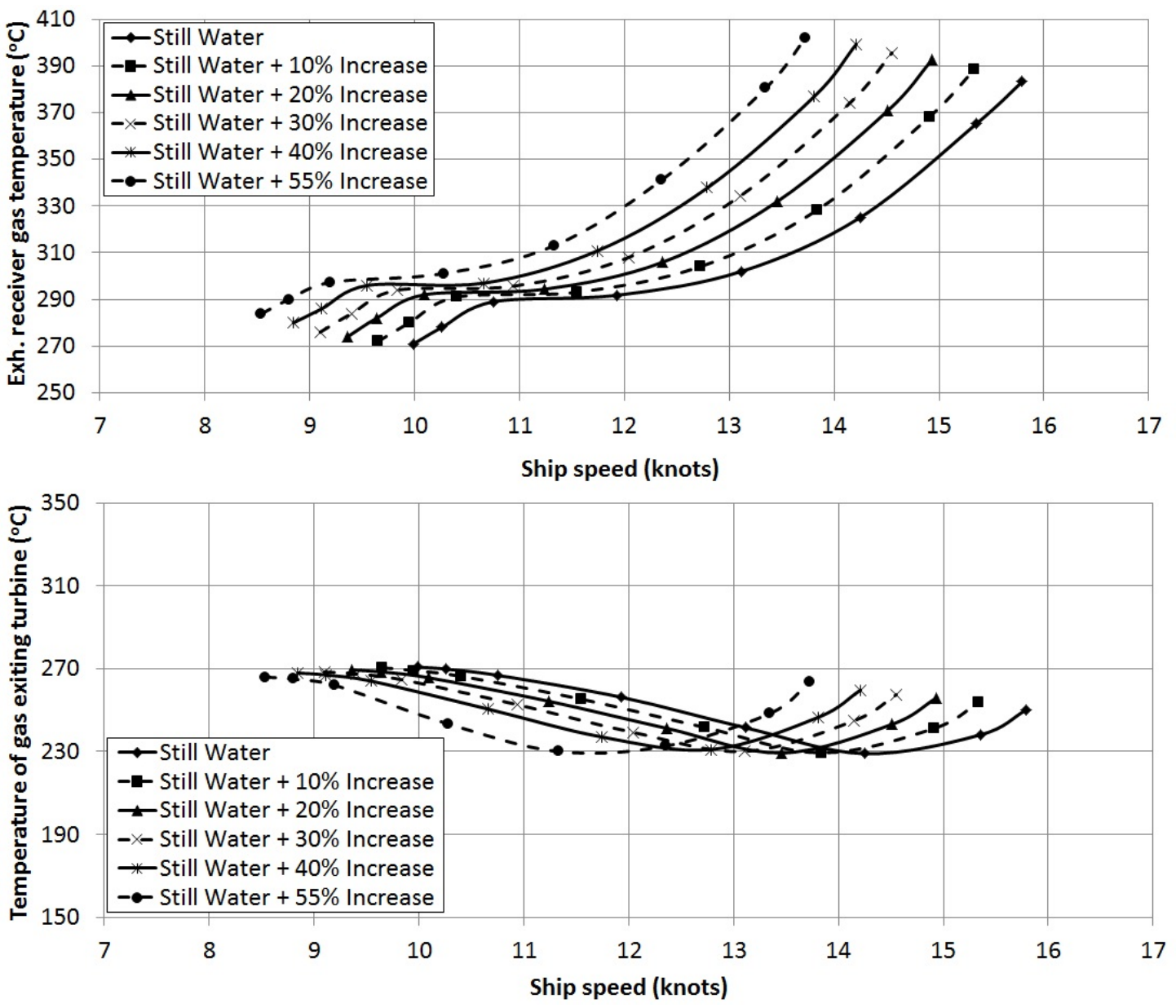

Figure 8: Exhaust receiver gas temperature (top) and temperature of the exhaust gas exiting the engine (bottom) vs. ship speed 

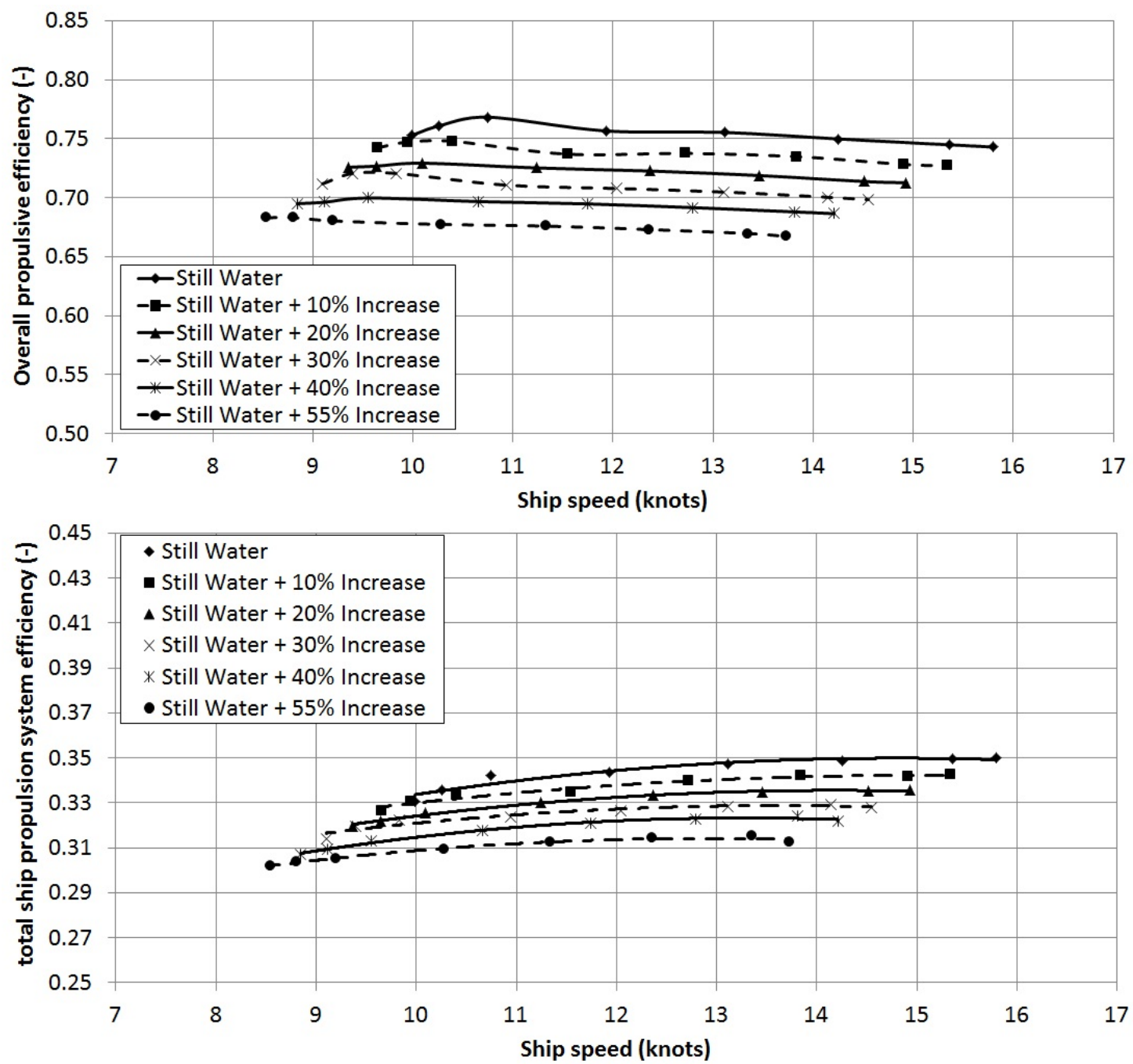

Figure 9: Overall ship propulsive efficiency (top) and total propulsion plant efficiency (bottom) vs. ship speed 

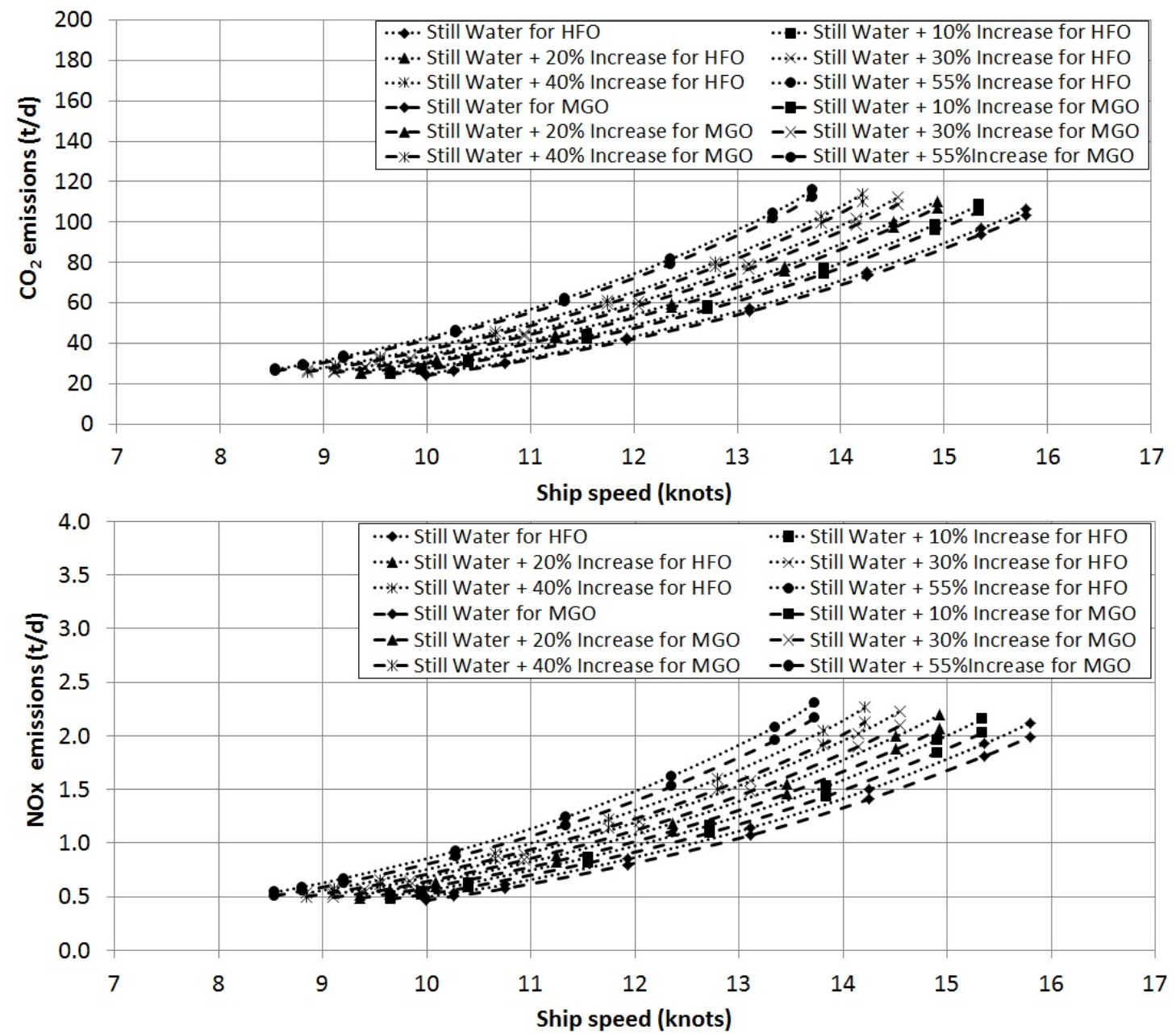

Figure 10: $\mathrm{CO}_{2}$ emissions (top) and NOx emissions (bottom) for HFO and low sulphur MGO vs. ship speed 



Figure 11: $\mathrm{SO}_{2}$ emissions for HFO (top) and low sulphur MGO (bottom) vs. ship speed 